Pesq. Vet. Bras. 31(6):543-550, junho 2011

\title{
Gross anatomical features of the oropharyngeal cavity of the ostrich (Struthio camelus) ${ }^{1}$
}

\author{
Catarina Tivane $e^{*}$, Marcio N. Rodrigues ${ }^{3}$, John T. Soley ${ }^{4}$ \\ and Herman B. Groenwald ${ }^{4}$
}

\begin{abstract}
Tivane C., Rodrigues M.N., Soley J.T. \& Groenwald H.B. 2011. Gross anatomical features of the oropharyngeal cavity of the ostrich (Struthio camelus). Pesquisa Veterinária Brasileira 31(6):543-550. Departamento Pré-Clinico, Faculdade de Veterinária, Universidade Eduardo Mondlane, Avenida de Moçambique, Km 1.5, Maputo, Mozambique. E-mail: catarina.tivane@uem.mz

Most descriptions of the ostrich oropharynx and oesophagus are superficial and supply little meaningful morphological data. The aim of this investigation is describe the ostrich oropharingeal cavity, in order to supply the deficiency of macroscopic data about this important animal. Five heads of 12 to 14-month-old ostriches of either sex were anatomically dissected to expose the oropharynx. The ostrich oropharynx was "bell-shaped" composed by the maxillary and mandibular ramphoteca. The roof and floor presented two distinct regions different in colour of the mucosa. The rostral region was pale pink contrasting to creamy-pink coloured caudal region. The median longitudinal ridge extended rostrally from the apex of the choana to the tip of the beak in the roof and it is clearly more prominent and rigid than the homolog in the floor that appeared thin and stretched rostrally, continuing caudally surrounding the tongue and the laryngeal mound eventually merging with the oesophageal mucosa. The floor was formed by the interramal region, tongue and laryngeal mound containing shield-shaped glottis. It can be concluded that the present study, in addition to confirming the basic features of the oropharynx previously described for the ostrich, clarified the contradictory information presented in the literature and also provided new, unreported morphological data, some of which may be important when studying nutrition and health in these birds.
\end{abstract}

INDEX TERMS: Anatomy, oropharynx, ostrich, Struthio camelus.

RESUMO.- [Características macroscópicas da cavidade orofaríngea de avestruz (Struthio camelus).] Os estudos já realizados sobre a cavidade orofaríngea da avestruz são escassos e não elucidam completamente sua morfologia. O objetivo desse estudo foi descrever macroscopicamente a cavidade orofaríngea de avestruzes com o

\footnotetext{
1 Received on July 20, 2010.

Accepted for publication on March 3, 2011.

${ }^{2}$ Departamento Pré-Clinico, Faculdade de Veterinária, Universidade Eduardo Mondlane, Avenida de Moçambique, Km 1.5, Maputo, Mozambique. ${ }^{*}$ Corresponding author: catarina.tivane@uem.mz

${ }^{3}$ Departamento de Cirurgia, Faculdade de Medicina Veterinária e Zootecnia (FMVZ-USP), Universidade de São Paulo (USP), Cidade Universitária, Av. Prof. Dr. Orlando Marques de Paiva 87, São Paulo SP 05508270, Brazil.

${ }^{4}$ Anatomy and Physiology Department, Faculty of Veterinary Science, University of Pretoria, Onderstepoort Campus, Private Bag X04, Onderstepoort, Pretoria 0110, South Africa.
}

intuito de suprir a deficiência de informação nesta espécie. Foram utilizadas 5 cabeças de avestruzes com doze a quatorze meses de idade dissecadas seguindo padrões anatômicos de modo a expor a orofaringe. A orofaringe de avestruzes tem formato de sino e é composta pelas ranfotecas maxilar e mandibular. $O$ teto e o assoalho apresentavam duas regiões distintas diferindo quanto à coloração da mucosa. A porção mais rostral era de coloração rosa pálida contrastando com a coloração mais fortemente rosada da porção mais caudal. A ruga palatina mediana estendia-se rostralmente do ápice da coana até a ponta do bico. No teto esta era mais proeminente e rígida que a do assoalho que se apresentava delgada e se estendia ao longo da porção rostral da região interramal, continuando caudalmente ao redor da coana e laringe e estendendo-se até o esôfago. $\mathrm{O}$ assoalho estava formado pela região interramal, língua e uma laringe com uma glote em forma de escudo. Pode-se concluir o presente estudo, além de 
confirmar as características básicas da orofaringe da avestruz previamente descritas, clarificam a informação contraditória presente na literatura e também novas informações morfológicas não previamente descritas são destacadas de forma a amparar outros estudos sobre a nutrição e saúde destas aves.

TERMOS DE INDEXAÇÃO: Anatomia, orofaringe, avestruz, Struthio camelus.

\section{INTRODUCTION}

The morphology of the bird oropharynx gained special attention in earlier descriptions of Göppert (1903) which compared this structure of numerous avian species. This study was later supported by McLelland (1979) who described in detail the structure of the oropharynx of many domestic species such as fowl, duck and goose (Ellenberger \& Baum 1943, Koch 1973, McLelland 1975, Nickel et al. 1977). The anatomy of this region in the turkeys reported to be similar to that of the chicken (McLelland 1975). Various other studies have concentrated on the description of specific morphological features of the region such as taste buds, Herbst corpuscles and salivary glands ((Lindenmaier \& Kare 1959, Winkelman \& Myers 1961, Warner et al. 1967, Anderson \& Nafstad 1968, Wight et al. 1970, Gentle 1971, Ziswiler \& Farner 1972, Gottschaldt \& Lausmann 1974, Iwasaki 2002, Wissman 2002) (see http://people.eku.edu/ ritchisong/ birddigestion.html). From the above-mentioned studies specific attention has been given to the tongue and larynx of birds, both structures forming much of the floor of the oropharynx. The morphological features of the avian tongue have been described in numerous species (see McLelland 1979 for a review of the earlier literature) and the structural adaptations of this organ linked to diet and mode of feeding (Lucas 1896, 1897, Gardner 1926, 1927). Many of these studies, particularly the earlier works, presented comparative information on the macroscopic features of the tongue with a view to providing taxonomic data (see eg. Lucas 1896, 1897, Gardner 1926, 1927). Recent studies have generally supplied more specific information on tongue structure by utilizing both light and electron microscopy in addition to macroscopic descriptions (Kobayashi et al. 1998, Jackowiak \& Godynicki 2005). The structure of the avian larynx has been detailed in a number of birds (Faraggiana 1933) including domestic species (Ziswiler \& Farner 1972, White 1975, Nickel et al. 1977).

Although Göppert (1903) provides a very accurate description and a sketch of the oropharynx of the ostrich, most descriptions of this region in ratites are superficial and supply little meaningful morphological data. Bezuidenhout (1999) briefly describes some basic features of the oropharynx in the ostrich whereas Duerden (1912) simply mentions that the tongue "is very short, blunt and nonprotrusable" and that in the "middle hinder part of the floor is a circular opening, the glottis" which opens into the trachea. Tadjali et al. (2008) studies although recent, do not provide complete description of the ostrich oropharynx (including tongue) in contrast to Gussekloo \& Bout, (2005) and Rodrigues (2009) descriptions in the rhea. The tongue and laryngeal mound of the ostrich, rhea and emu have also been described and illustrated in some detail by Faraggiana (1933) and Rodrigues (2009), from were brief descriptions (generally defining the shape) of the ostrich, rhea, emu and cassowary tongue have been published (Gadow 1879, Feder 1972, Cho et al. 1984, Fowler 1991, Tadjali et al. 2008, Crole \& Soley 2010).

In view of the lack of meaningful information regarding the gross anatomical features of the upper digestive tract of the ostrich, this study provides a detailed description of the macroscopic features of the oral cavity (including the tongue) and pharynx (including the laryngeal mound) and compares the results with published information on ratites and, where appropriate, with birds in general. The terminology used is that of Nomina Anatomica Avium (Baumel et al. 1993).

\section{MATERIALS AND METHODS}

The heads of five 12 to 14-month-old ostriches of either sex were obtained from a local ostrich abattoir (Ostriches Galore, Krugersdorp, Gauteng, South Africa) where the birds were slaughtered for their skin and meat. After the heads had been removed from the carcasses they were immediately immersed in plastic buckets containing $10 \%$ buffered formalin and allowed to fix for approximately 4 hours while being transported to the laboratory. At the laboratory the specimens were immersed in fresh fixative (10\% buffered formalin) for a minimum period of 48 hours. The heads were then removed from the fixative, rinsed in running tap water to remove excess of formalin, and incised along one comissure of the mouth to expose the oropharyngeal cavity. The macroscopical features were mdescribed and digitally recorded using Nikon coolpix 995 digital camera (Nikon, Tokyo, Japan). Dried skulls and whole specimens of the tongue, laryngeal mound, trachea and hyoid bone were utilized to provide supporting evidence of the gross anatomical description.

\section{RESULTS \\ Rostral boundaries of the oropharynx}

The oropharyngeal cavity was bell-shaped (Fig.1) and dorso-ventrally flattened, resulting in limited space within the cavity when the beak was closed. No obvious morphological distinction could be made between the oral cavity and the pharynx and both cavities formed a common chamber.

The rostral part of the oropharynx was bounded ventrally by the mandibular ramphotheca and dorsally by the maxillary ramphotheca. The mandibular ramphotheca was a pale, creamy colour and was clearly demarcated from the rest of the floor of the oral cavity with which it was continuous. It extended bilaterally as a zone of cornified epithelium from the angulus oris. The ramphotheca was of equal width where it lay over the ramus of the mandible but widened rostrally to form a plate-like region above the mandibular rostrum (rostrum mandibulae) (Fig.1). A variable number of fine, rostro- laterally oriented folds continuous with the mucosal folds on the inter-ramal region were observed on the mandibular ramphotheca, and a raised, 
sharp edge, the tomium (tomium mandibulare) was apparent along the lateral border of the rostral half. At the tip of the beak the tomium was interrupted by the rostral termination of the gonys, a midventral, thickened, plate-like component of the external ramphotheca which extended from the tip of the mandible to the skin forming the rostral limit of the inter-ramal region. The gonys was supported by a broad thickening of the bone on the ventral surface of the mandibular rostrum in the vicinity of the mandibular symphysis (symphysis mandibularis). The termination of the gonys effectively formed the unguis or nail which was continuous with the tomium, of similar height and varied in width between $12-15 \mathrm{~mm}$. A short region of the mandibular tomium just caudal to the tip of the beak was finely serrated. The remaining lateral surface of the mandibular ramphotheca caudal to the tomium was smooth and rounded (Fig.1-2).

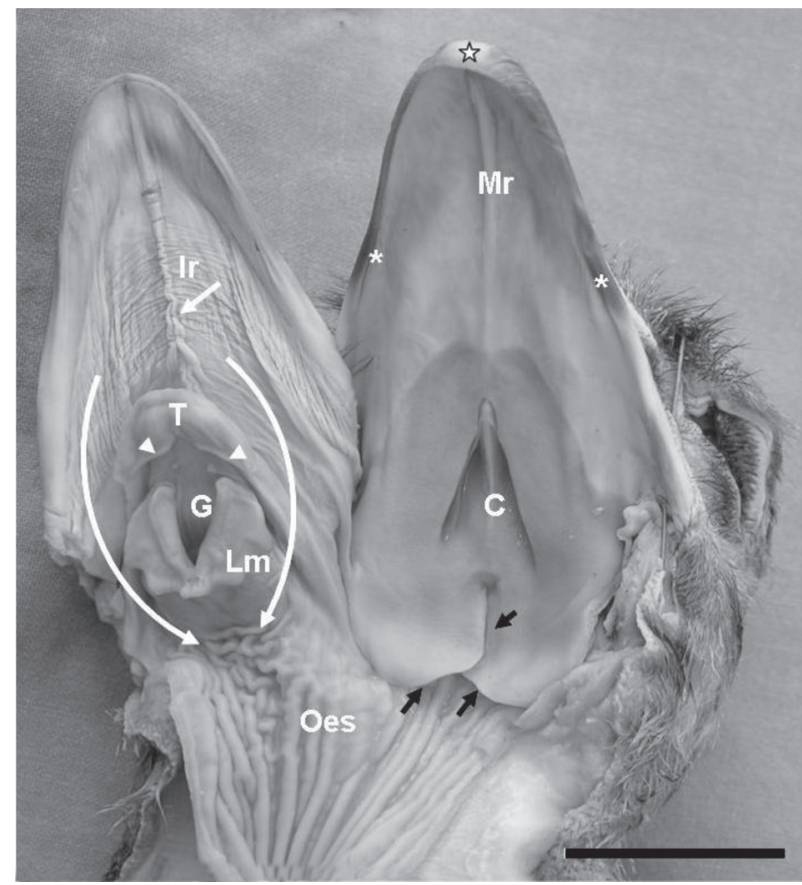

Fig.1. Macroscopic features of the oropharyngeal cavity of the ostrich. The maxillary ramphotheca (asterisks) are narrower than the mandibular ramphotheca (double asterisks). Note the contribution of the culmen (star) to the tomium of the upper beak. The roof of the oropharynx displays a median palatine ridge (Mr), a pale rostral component (Rc) and darker caudal component (Cc), the bell-shaped choana (C) and the infundibular cleft (black arrow-head). Note the overlapping pharyngeal folds (Pf) on either side of the cleft and the retro-pharyngeal recess (black arrows), these folds are continuous with the proximal oesophagus (Oes). The floor of the oropharynx shows the highly folded interramal region (Ir) exhibiting a large median fold (white arrow). The folds proceed caudally around the tongue $(T)$ and laryngeal mound $(\mathrm{Lm})$ to the proximal oesophagus as indicated by the curved arrows. Observe the point of reflection of the dorsal surface of the tongue to form a deep pocket (arrowheads). The laryngeal mound displays three pairs of projections and the V-shaped glottis $(\mathrm{G})$.

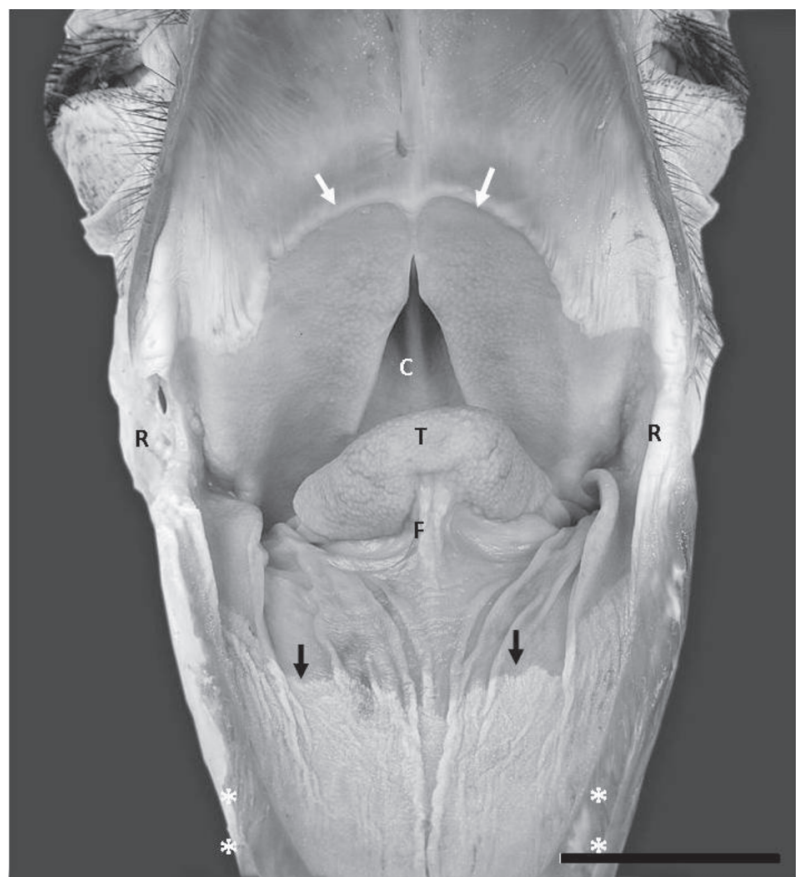

Fig.2. Maximum gape of the mouth revealing the caudal aspect of the oropharynx in the ostrich. The tongue has been retracted from the floor of the oropharynx to expose the non-glandular mucosa (pale colour) lying beneath and lateral to the tongue. The abrupt transition from non-glandular to a glandular mucosa (light brown colour) is clear (black arrows). A similar colour transition is seen on the roof of the oropharynx (white arrows). Note the cobblestone appearance (probably indicated the openings of the glands) in the region around the choanae $(\mathrm{C})$ and in the tongue $(\mathrm{T})$. Note the numerous folds on the floor of the oropharynx (interramal region) and the frenulum $(F)$. Both sets of ramphotheca are rounded at their caudal aspect and terminate at the rictus (R). The mandibular ramphotheca (double asterisks) are visibly wider than the maxillary ramphotheca.

The maxillary ramphotheca was not as clearly demarcated from the surrounding tissue when compared to the mandibular ramphotheca. As in the latter, the tomium was only apparent along the rostral half of the maxillary ramphotheca. The lateral margin of the caudal maxillary ramphotheca formed a rounded, cord-like structure which extended to the corners of the mouth (Fig.1-2). At the tip of the beak the tomium was interrupted by the rostral termination of the culmen (a mid-dorsal plate of the external ramphotheca which extended from the tip of the upper beak to the skin of the forehead) (Fig.1) in similar fashion to that observed on the mandible. This structure (maxillary unguis or nail) was also continuous with the tomium, again of similar height and varied in width of $12-13 \mathrm{~mm}$. The rostral part of the maxillary tomium and the maxillary unguis exhibited a higher profile than the equivalent structures on the mandible. The rostral part of the culmen was supported by a thickening of the dorsal tip of the premaxillary bone providing further support that the termination of the culmen formed a nail (unguis). 


\section{Roof of the oropharynx}

The roof of the cavity demonstrated two regions (of approximately equal area) based on differences in the colour of the mucosa. The demarcation of the two regions was abrupt (Fig.1-2). The mucosa of the rostral and rostro-lateral region was pale and tightly stretched, and divided into two halves by a prominent raised longitudinal mucosal ridge or fold, the median palatine ridge (Ruga palatina mediana) that extended rostrally from the apex of the choana to the tip of the beak, ending against the unguis. The tip of the ridge narrowed into a sharp point and flattened, effectively subdividing the ramphotheca above the maxillary rostrum into two halves (Fig.1). At a point approximately half way along the median ridge the mucosa in this region displayed fine, oblique mucosal folds which radiated rostro-laterally towards the rampotheca where they became progressively larger. Light Microscopy (LM) revealed that the mucosa in this region was non-glandular.

The mucosa of the caudal and caudo-medial region was darker in colour, had a sponge-like texture and surrounded the choana and opening of the "Eustachian" tubes. When viewed from beneath, the choana formed inverted V-shaped depression subdivided along the midline by a prominent mucosal ridge. The ridge was deeper rostrally where it inserted arrowhead-like into the apex of the choana (Fig.3A). It became shallower caudally where it expanded just beneath the caudal border of the choana to form a shallow crescent that demarcated the rostral boundary of the infundibular cleft. At the lateral borders of the choana lay the openings of the internal nares, each demarcated dorso-medially by a low mucosal ridge. This ridge formed the lateral border of a relatively deep, blind-ending mucosal recess (Fig.1-3).

Caudal to the choana was the median infundibular cleft (Rima infundibuli) which represented the opening to the pharynx of the infundibulum into which, in turn, the left and right "Eustachian" tubes opened. The infundibular cleft extended from a crater-like depression lying caudal to the crescent-shaped ridge described above and continued caudally to subdivide the caudal portion of the pharyngeal mucosa into two overlapping mucosal (pharyngeal) folds. The free borders of the folds were rounded and each contributed to the formation of a deep retro-pharyngeal recess which was continuous with the longitudinally folded mucosa of the oesophagus (Fig.1-3). The thickened nature of the mucosa in this region was due to the presence of numerous, well-developed mucous-producing glands as revealed later by LM. The openings of these glands could
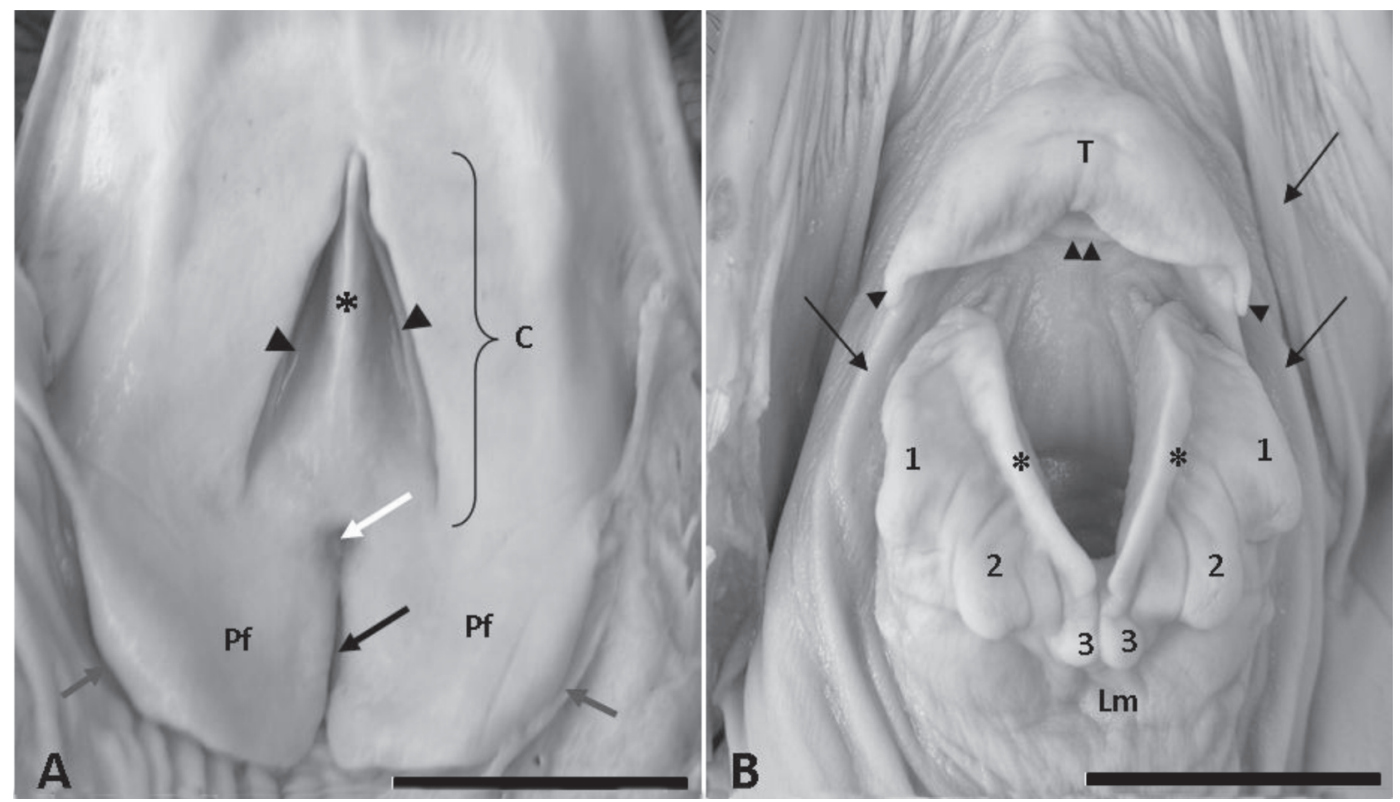

Fig.3. (A) Enlargement of the caudal region of the roof of the oropharynx. In A illustrating the choana (C) which form a inverted $\mathrm{V}$-shaped depression subdivided along the midline by a prominent mucosal ridge (asterisk). The openings of the internal nares are demarcated dorso-medially by low mucosal ridges (arrow-heads). The infundibular cleft (black arrow) extends from a crater-like depression (white arrow) to subdivide the caudal portion of the pharynx into two overlapping mucosal (pharyngeal) folds (Pf). The free borders of the folds are rounded and form a deep retropharyngeal recess (grey arrows) before becoming continuous with the mucosa of the proximal oesophagus. (B) The caudal region of the floor of the oropharynx showing details of the tongue $(\mathrm{T})$ and laryngeal mound ( $\mathrm{Lm})$. Note the two small caudally directed papillae at the base of the tongue (arrowheads) and the secondary tongue fold (double arrowhead). The elevated lips of the glottis (asterisks) are prominent and the three pairs of projections (1,2 and 3) on that part of the mound formed by the arytenoid cartilages appear in the form of papillae. The caudo-medial projections (3) are clearly separated in this specimen. 
be seen as small pit-like depressions throughout the surface of this region, particularly in the vicinity of the pharyngeal folds.

\section{Floor of the oropharynx}

The floor of the oropharynx was formed by the interramal region (Regio interramalis), the tongue and the laryngeal mound (Fig.1). The triangular interramal region was accommodated between the rami of the mandible and formed the floor of the oral cavity rostral to the tongue. It extended bilaterally around both the tongue and the laryngeal mound, eventually merging with the oesophageal mucosa. The mucosa of this region displayed two components based on differences in colour. The largest component was a pale colour and occupied the rostral and rostro-lateral aspects of the oral cavity. (Fig.1-2). The smaller creamy-pink component (darker) (also non-glandular but with a thicker epithelial component as shown by LM) occupied a limited area in the immediate vicinity of the tongue, both rostrally and laterally (Fig.1-2), curved around the laryngeal mound, and represented that part of the interramal region that merged with the oesophageal mucosa.

The entire interramal region was characterised by a series of mucosal folds, the most obvious of which was a median longitudinal fold running from beneath the tongue to the tip of the mandibular ramphotheca. This fold originated in the darker region of the interramal mucosa as two moderately sized latero-medial folds that converged on the midline where they met, at the junction between the darker and lighter mucosa, with two smaller medial folds to form a pair of larger median folds. These folds in turn merged approximately half-way along the interramal region to form a single fold which enlarged appreciably within the relatively smooth rostral termination of the interramal region. In similar fashion to that of the median palatine ridge, this fold continued rostrally, effectively dividing the ramphotheca covering the mandibular rostrum into two halves before narrowing to terminate against the mandibular unguis. Unlike the median palatine ridge, the greater part of the median fold and its components were fleshy in nature and displayed a zig-zag pattern. The rostral part of the fold, however, was more rigid and showed no folding (Fig.1-2).

Two additional sets of folds were observed to originate from the floor of the pharynx on either side of the laryngeal mound. Each set consisted of approximately four longitudinal folds, the largest of which was laterally positioned and emanated from the rostro-lateral border of the overlying pharyngeal fold. This tall, fleshy fold ran along the lateral aspect of the interramal region but was separated from the ramphotheca of the mandibular ramus by a deep, narrow cleft. The fold terminated at approximately the level of the tip of the tongue in the form of a number of small radiating folds traversing the aglandular mucosa. In addition, small obliquely oriented folds branched from the main fold along much of its length, those extending from the lateral aspect of the main fold running onto the mandibular ramphotheca. The most medially positioned of the folds was also large and fleshy in nature and extended from the caudal and caudo-lateral aspects of the body of the tongue, coursing around the laryngeal mound to merge with the criss-crossing folds of the widened portion of the proximal oesophagus. This fold formed a deep recess between itself and the laryngeal mound (Fig.1 and 3B).

Positioned between the large medial and lateral folds were two or more smaller folds that were continuous with the proximal oesophagus and which branched rostrally onto the mucosa of the interramal region (Fig.1-2). Although most of the smaller folds in this region were longitudinally oriented, numerous oblique and transverse folds were observed to link the three major sets of longitudinal folds.

The ostrich tongue was a small, stubby, U-shaped structure that lay approximately in the middle of the floor of the oropharynx. It was a pale, creamy pink colour in formalin-fixed specimens and had a firm texture. From the blunt apex the body widened caudally forming two short arms, each of which terminated in an elongated, relatively slender, rounded tip reminiscent of a papilla (Fig.1-3). The base of the tongue lay relatively far from the entrance of the larynx (the glottis) and the stretch of mucosa lying between the two structures demonstrated a number of longitudinal folds (Fig.3B). Whether this region represented the root of the tongue was morphologically difficult to determine. With the beak closed the tongue fitted snugly against the glandular mucosa around the rostral aspect of the choanae. The stubby, thickened nature of the tongue resulted of the formation of dorsal, ventral and lateral surfaces, each of which displayed a subtle, cobblestone appearance (Fig.2). Were believe that each rounded unit (cobblestone) contained a centrally positioned opening which represented the duct of large mucus-producing glandular units situated in the mucosa.

The dorsal surface of the tongue was folded back on itself resulting or the formation of a deep, blind-ending pocket. Median sections of the tongue revealed that the "pocket" was divided into dorsal and ventral recesses by a relatively large secondary mucosal fold (Fig.4). There was no communication between the two recesses and both opened caudally opposite the entrance to the glottis. The ventral aspect of the tongue was attached to the floor of the oropharynx by the frenulum (frenulum linguae) which was triangular in shape. The broad base of the frenulum was caudally positioned with the apex directed rostrally. A shallow recess lay at the junction between the frenulum and the ventrum of the tongue and a shallow median sulcus was apparent towards the tip of the ventrum. The smooth mucosa of the frenulum commonly displayed numerous folds with oblique and longitudinal folds being particularly obvious along the lateral edges (Fig.2). It was also clear from median sections that the body of the tongue was supported by the paired cartilaginous paraglossals and the cartilaginous rostral process of the basihyale, whereas the root was supported by the ossified body of the basihyale and rostral process of the cricoid cartilage of the larynx. 


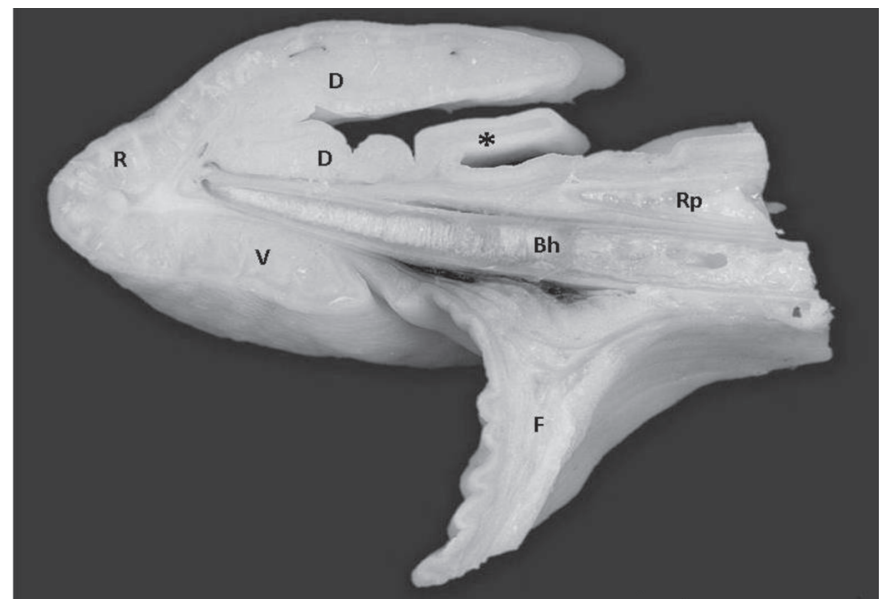

Fig.4. A mid-saggital section through the tongue showing the blunt rostral aspect $(R)$, the dorsal surface $(D)$ folded back on itself, forming a pocket divided into dorsal and ventral recesses by a secondary mucosal fold (asterisk), the ventral surface $(\mathrm{V})$ and the frenulum $(\mathrm{F})$. The basihyale $(\mathrm{Bh})$ and more dorsally positioned rostral process (Rp) of the cricoid cartilage form supporting structures for the tongue.

A short distance from the base of the tongue was the laryngeal mound, a raised, oval or shield-shaped structure which occupied the caudal third of the floor of the oropharyngeal cavity. It was related rostrally to the base of the tongue and caudally to the oesophagus. The more rostral star-shaped portion of the mound housed the glottis which in fixed specimens was opened wide in a V-shaped configuration, with the arms of the $\mathrm{V}$ directed rostro-laterally (Fig.1 and 3B). The rim of the glottis was demarcated by two prominent mucosal ridges or lips which were elevated above the surface of the mound. The ridges did not meet at the base of the glottis, leaving a small gap between them (Fig.3B). When the beak was closed, the glottis was perfectly aligned with the common openings of the choana.

The star-shaped portion of the mound housing the glottis was inclined in a dorso-rostral direction giving it a horizontal orientation in respect of the rostral portion of the oropharyngeal cavity and was characterized by the presence of three pairs of prominent projections that gave it a starshaped appearance. The rostral pair was laterally directed whereas the caudal and caudo-medial pairs were caudally directed (Fig.1 and 3B). The caudo-medial pair were closely apposed and in some specimens appeared to form a single structure, although a subtle medial groove could be discerned (Fig.3B). The paired rostral and caudal projections were supported by extensions of the arytenoid cartilages whereas it appeared as if the caudo-medial projections existed simply as mucosal extensions. The more caudal aspect of the laryngeal mound was structurally uncomplicated and visibly represented that portion of the larynx supported by the cricoid cartilage. The mucosa covering the mound was relatively smooth in appearance and was continuous caudally with the prominently folded mucosa of the oesophagus.

\section{DISCUSSION}

\section{General features}

The boundaries and components of the oral and pharyngeal cavities of the ostrich agree with the general avian pattern as previously described (Göppert 1903, Farner \& King 1972, McLelland 1979, 1993) and with the brief description of Bezuidenhout (1999). As noted above, no obvious morphological distinction could be made between the oral cavity and the pharynx and both cavities formed a common chamber. This situation is apparent in most avian species due to the absence of a soft palate and oropharyngeal isthmus (McLelland, 1979, 1993). However, Zweers et al. (1977) (cited by McLelland 1993), place the boundary between both cavities in the duck at the level of the caudal lingual papillae. Employing embryological data, it has been suggested (Lucas \& Stettenheim 1972, cited by McLelland 1993) that the dorsal transverse boundary lays between the choana and the rima infundibuli, stretching laterally to the angles of the jaws, and that the ventral transverse boundary lays between the paraglossal and basihyal bones.

The ramphotheca forming the rim of the oral cavity in ratites reportedly "shows very little adaptation and the rims are relatively rounded and blunted" (Gussekloo 2006). This is certainly true for the caudal aspect of the ramphotheca in the ostrich. However, the more rostral component of both the mandibular and maxillary ramphotheca shows a raised, sharp edge, the tomium located along the lateral border. The existence of this structural adaptation would lend support to the observation that ostriches use their large beaks to tear off plant material (Brand \& Gous 2006). The distinct difference in width observed between the mandibular and maxillary ramphotheca in the ostrich has also been illustrated in the rhea (Gussekloo \& Bout 2005).

\section{Roof of the oropharynx}

The roof of the oropharynx exhibited the basic features previously described and illustrated in the ostrich by Göppert (1903). In contrast to various other avian species, where the mucosa of the palate frequently forms lateral, median and intermediate ridges (McLelland 1979), the mucosa of the palate in the ostrich formed a single median longitudinal ridge (ruga palatina mediana) which extended the length of the palate rostral to the tip of the choana. A similar, single median ridge is also illustrated in the palate of the rhea (Gussekloo \& Bout 2005, Gussekloo 2006) and the emu (Crole \& Soley 2010). As illustrated by Göppert (1903) and confirmed in the present study, the choana in the ostrich is very short and restricted to the caudal aspect of the palate, a feature shared with a few other species such as herons and ducks (McLelland 1979). The illustration of the oropharynx of the rhea provided by Gussekloo \& Bout (2005) also indicates a similar situation in this species. Likewise, as determined in the present study, the caudally directed papillae that reportedly form a typical feature of the palate and roof of the pharynx in many avian species (Göppert 1903, McLelland 1979) are totally absent in the ostrich and 
apparently also in the rhea (Gussekloo \& Bout 2005). An interesting finding from the present study was the division of the palate into two distinct regions based on differences in the colour of the mucosa. The illustration of the ostrich oropharynx by Göppert (1903) also appears to indicate this regional differentiation. However, contrary situation have been described by Crole \& Soley (2010) in the emu were the authors demonstrated that the rostral region was pigmented in contrast to non-pigmented caudal region.

The most distinct features of the pharynx observed in this study and also by Göppert (1903) were the presence of large pharyngeal folds and a long pharyngeal cleft (Rima infundibuli). The pharyngeal cleft is described as a median longitudinal fissure which connects the infundibulum (into which the Eustachian tubes [Tubae auditivae] open) to the pharynx (McLelland 1979, 1993). The observation that the auditory tubes open independently into the infundibulum in ratites, as opposed to opening via a common tube as in the chicken and dove) (McLelland 1993) was not confirmed in the present study. The massive pharyngeal folds in the ostrich were seen to overlap on the midline as also noted by McLelland (1979). McLelland (1979) stated that these folds make "a sharp boundary with the oesophagus". Although this appears to be the case when viewed macroscopically, the statement is misleading as this study demonstrated that the pharyngeal folds form a deep recess before merging with the tissue of the proximal oesophagus.

\section{Floor of the oropharynx}

This study demonstrated that the floor of the oropharynx of the ostrich consisted of three components, the interramal region (regio interramalis), the tongue and the laryngeal mound (mons laryngealis).

The triangular interramal region has previously been mentioned or illustrated in the ostrich (Göppert 1903, Bezuidenhout 1999). The present study identified this region as being heavily folded, with the most prominent feature being a double/single large median mucosal fold that effectively divided the interramal region into two halves. A similar, but in this instance single median fold, is also illustrated in the interramal region of the rhea (Gussekloo \& Bout 2005, Gussekloo 2006). It has been noted that in birds equipped with oral sacs for carrying food, the inner wall of the sacs is greatly folded in the empty state to allow for expansion when filled (Bock et al. 1973). The presence of a highly folded mucosa would indicate that the interramal region in the ostrich is therefore capable of a degree of distension to accommodate the accumulation of food in the oral cavity prior to swallowing. The scooping of water into the beak during drinking would also require temporary storage in the interramal region (distension therefore important) prior to the water moving to the proximal oesophagus where it is accumulated until the head is raised (F. W. Huchzermeyer. personal communication). The deep gullies formed between the mucosal folds that run around the tongue and laryngeal mound would also act to channel the water to the proximal oesophagus.
This study confirmed the basic observation by previous authors (Gadow 1879, Göppert 1903, Duerden 1912, Cho et al. 1984, Bezuidenhout 1999) that the ostrich tongue is small, triangular or U-shaped, has a smooth appearance and is non-pigmented, and also that the dorsal surface folds back on itself to form a pouch or pocket (Göppert 1903, Faraggiana 1933, Fowler 1991). Although smooth, the surface of the ostrich tongue has a cobble-stone appearance due to the presence of large mucus-producing glands located just beneath the surface. Faraggiana (1933) made a similar observation, noting that the tongue surface is composed of many tightly-packed semi-circular papillae. This feature has not been noted in any other previous investigations.

The present paper also confirmed the observations of Göppert (1903) and Faraggiana (1933) that the caudal aspect of the body of the tongue tapered bilaterally to form papillae-like extensions. It is well documented that in many avian species, including domestic birds, the tongue is adorned with lingual papillae (see, for example, Göppert 1903, Gardner 1926, 1927, Nickel et al. 1977, McLelland 1979, Kobayashi et al. 1998). However, the situation in ratites is less clear and conflicting information has been presented regarding the presence of lingual papillae. Gussekloo (2006) notes that in ratites "only the papillae behind the larynx (papillae pharyngis caudoventrales) are clearly recognizable", whereas Tomlinson (2000), commenting on the role of the ratite tongue in pushing a food bolus from the pharynx to the oesophagus, states that "The tongue is therefore very short and relatively broad without clear adaptations other than the papillae linguae caudales that stabilize the food bolus during the final transport into the oesophagus." The structures seen in some specimens of the ostrich tongue certainly resemble papillae (caudal lingual papillae) and it would appear as if a similar structural adaptation occurs in the rhea (Rhea americana) tongue (sketch by Gussekloo \& Bout 2005, Rodrigues 2009). The paired papillae-like extensions at the base of the ostrich tongue are poorly developed in comparison to those observed in the rhea and whether they represent true lingual papillae is not clear. Lingual papillae are generally accepted to assist in swallowing food, but in the ratites where the small tongue is viewed as a rudimentary organ adapted for the rapid swallowing of bulky food items (McLelland 1979), the assistance of the weakly developed papillae in the ostrich may be of limited value. In the emu the serrated edge described by Cho et al. (1984) certainly represents lingual papillae. Additional observations in the emu have revealed that both lateral and caudal sets of papillae are indeed present and well-developed in this species (Crole \& Soley 2010). Gadow (1879) notes that the lateral edges of the cassowary tongue carry small, caudally directed points which would also appear to represent lingual papillae.

The folded nature of the ostrich tongue has previously been described (Göppert 1903, Faraggiana 1933, Fowler 1991). In addition to confirming this observation, the present study revealed that the deep pouch formed by the dorsal 
tongue fold is further subdivided by a smaller, but substantial secondary fold, into dorsal and ventral recesses. The function of this structural adaptation is unclear but the large increase in surface area produced by the folds, and by virtue of the numerous mucus producing glands found in the mucosa, would presumably enhance mucus production and secretion required for ingesting often dry and difficult to swallow plant material. As noted by Gussekloo (2006) "The products of the salivary glands [in birds] have functions in the intraoral transport (e.g. in slide-and-glue transport), but mainly in the lubrication of food."

The laryngeal mound (Mons laryngealis) in avian species is a raised structure lying immediately caudal to the tongue and which carries on its rostral aspect the glottis (McLelland 1979). Similar to most bird species, the laryngeal mound in the ostrich was situated close to the base of the tongue with only a small stretch of intervening tissue lying between the two structures (McLelland 1979). In the ostrich the part of the mound carrying the glottis (supported by the arytenoid cartilages) was a star-or shield-shaped structure, characteristic features that were also illustrated by Göppert (1903) and Faraggiana (1933). The glottis typically lay directly opposite the caudal aspect of the choana as described for most avian species (McLelland 1979). The observation in the ostrich that the lips of the glottis did not meet at the base was also illustrated by Faraggiana (1933). It has been well documented that in most species of birds, papillae are found in the oropharynx at the edges of the choana, the base of the tongue, caudal to the larynx and infundibular cleft (Göppert 1903, McLelland 1979, Gussekloo 2006). However, in ratites, according to Gussekloo (2006), the only papillae which can be readily recognized are those situated at the base of the larynx (papillae pharyngis caudoventrales). Compared to other birds, it is clear that the oropharynx of the ostrich (and ratites in general) is poorly equipped with papillae. In conclusion some structural differences and similarities between the ostrich oropharynx and other bird species were determined in the present study. However, important morphological information not previously described is highlighted in order to support further studies on these birds.

\section{REFERENCES}

Baumel J.J., King A.S., Breazile J.E., Evans H.E. \& Vanden Berge J.C. 1993. Handbook of Avian Anatomy: Nomina Anatomica Avium. $2^{\text {nd }}$ ed. Nuttall Ornithological Club, Cambridge, Massachusetts, 799p.

Bezuidenhout A.J. 1999. Anatomy, p.13-49. In: Deeming D.C. (Ed.), The Ostrich: Biology, production and health. CABI Publishing, Wallingford, UK.

Bock W.J., Balda R.P. \& Vander Wall S.B. 1973. Morphology of the sublingual pouch and tongue musculature in Clark's Nutcracker. Auk. 90:491-519.

Brand T.S. \& Gous R.M. 2006. Feeding ostriches, p.136-155. In: Bels V. (Ed.), Feeding in Domestic Vertebrates: From structure to behaviour. CABI Publishing, Wallingford, UK.

Cho P., Brown B. \& Anderson M. 1984. Comparative gross anatomy of ratites. Zoo Biology 3:133-144.
Duerden J.E. 1912. Experiments with ostriches. XVIII. The anatomy and physiology of the ostrich. A. The external characters. Agric. J. Union S. Africa. 3:22-29.

Ellenberger W. \& Baum H. 1943. Handbuch der vergleichenden Anatomie der Haustiere. 18. Aufl. Springer-Verlag, Berlin.

Faraggiana R. 1933. Sulla morfologia della lingua e del rialzo laringeo di alcune specie di Uccelli Ratiti e Carenati non comuni. Bollettino dei Musei di Zoologia e Anatomia Comparata, Università di Torino, 43:313323.

Farner D.S. \& King J. R. 1972. Avian Biology (K. Parkes, Ed.). Vol.2. Academic Press, Pittsburgh, Pennsylvania, p.343-364.

Feder F.H. 1972. Zur mikroskopischen Anatomie des Verdauungsapparates beim Nandu (Rhea americana). Anatomischer Anzeiger 132:250-265.

Fowler M.E. 1991. Comparative clinical anatomy of ratites. J. Zoo Wildl. Med. 22:204-227.

Gadow H. 1879. Versuch einer vergleichenden Anatomie des Verdauungssystemes der Vögel. Jenaische Zeitschrift für Medizin und Naturwissenschaft 13:92-171.

Gardner L.L. 1926. The adaptive modifications and the taxonomic value of the tongue in birds. Proc. United States National Museum 67, Article 19.

Gardner L.L. 1927. On the tongue in birds. Ibis 3:185-196.

Göppert E. 1903. Die Bedeutung der Zunge für den sekundären Gaumen und den Ductus naso-pahryngeus. Morphologische Jahrbuch 31:311-359.

Gussekloo S.W.S. 2006. Feeding structures in birds, p.14-32. In: Bels V. (Ed.), Feeding in Domestic Vertebrates: From Structure to behavior. CABI Publishing, Wallingford, UK.

Gussekloo S.W.S. \& Bout G.R. 2005. The kinematics of feeding and drinking in palaeognathous birds in relation to cranial morphology. J. Exp. Biol. 208:3395-3407.

Jackowiak H. \& Godynicki S. 2005. Light and scanning electron microscopic study of the tongue in the white tailed eagle (Haliaetus albicilla, Accipitiridae, Aves). Annals of Anatomy 187:251-259.

Koch T. 1973. Anatomy of the Chicken and Domestic Birds. lowa State University Press, Ames, lowa.

Kobayashi K., Kumakura M., Yoshimura K., Inatomi M. \& Asami T. 1998. Fine structure of the tongue and lingual papillae of the penguin. Archivum Histologicum Cytologicum 61:37-46.

Lucas F.A. 1896. The taxonomic value of the tongue in birds. Auk 13:109-115.

Lucas F.A. 1897. The tongues of birds. Report of the United States National Museum, p.1003-1020.

McLelland J. 1975. Avian digestive system, p.1857-1882. In: Getty R. (Ed.), Sisson and Grossman's The Anatomy of the Domestic Animals. Vol.2. W.B. Saunders, Philadelphia.

McLelland J. 1979. Digestive system, p.69-81. In: King A.S. \& McLelland J. (Eds), Form and Function in Birds. Vol.1. Academic Press, London.

McLelland J. 1993. Apparatus Digestorius [Systema Alimentarium]. In: Baumel J.J., King A.S., Breazile J.E., Evans H.E. \& Van den Berge J.C. (Eds), Handbook of Avian Anatomy: Nomina Anatomica Avium. $2^{\text {nd }}$ ed. Nuttall Ornithological Club, Cambridge, Massachusetts.

Nickel R., Schummer A. \& Seiferle E. 1977. Anatomy of the Domestic Birds. Vol.5. Verlag Paul Parey, Berlin. 202p.

Tomlinson C.A. 2000. Feeding in palaeognathous birds, p.359-394. In: Schwenk K. (Ed.), Feeding: Form, function, and evolution in tetrapod vertebrates. Academic Press, San Diego.

White S.S. 1975. The larynx, p.1891-1897. In: Getty R. (Ed.), Sisson and Grossman's The Anatomy of the Domestic Animals Vol.2. W.B. Saunders, Philadelphia.

Ziswiler V. \& Farner D.S. 1972. Digestion and the digestive system, p.343-364. In: Farner D.S. \& King J.R. (Eds), Avian Biology. Vol.2. Academic Press, New York. 